\title{
Level of Knowledge and Practice of Manual Therapy among Physiotherapy Practitioners at the University Teaching Hospital, Lusaka, Zambia
}

\author{
Gracious Chavula \\ School of Health Sciences, Ridgeway Campus, The University of Zambia, P.O. Box 50110, Lusaka, Zambia.
}

How to cite this paper: Gracious Chavula. (2022) Level of Knowledge and Practice of Manual Therapy among Physiotherapy Practitioners at the University Teaching Hospital, Lusaka, Zambia. International Journal of Clinical and Experimental Medicine Research, 6(2), 103-110. DOI: 10.26855/ijcemr.2022.04.001

Received: December 23, 2021

Accepted: January 18, 2022

Published: February 14, 2022

*Corresponding author: Gracious Chavula, School of Health Sciences, Ridgeway Campus, The University of Zambia, P.O. Box 50110, Lusaka, Zambia.

Email: graciouschavula21@gmail.com

\begin{abstract}
Manual therapy has been a component of physical rehabilitation programs as early as $400 \mathrm{BC}$, including mobilization/manipulation being a component of physiotherapy practice. However, manual therapy can be a major aspect of the treatment protocols. Despite the growing body of evidence for manual therapy, it is viewed as a complementary therapy in human medicine by many, even though its effectiveness seems well substantiated and the risks are low. The most likely reason for its slow acceptance is that the skill level required to apply these techniques properly is higher than with traditional therapies, such as exercise or electrotherapy. Physiotherapy practitioners' knowledge and practice of manual therapy are very fundamental in ensuring effective treatment of the patient. This study was designed to determine the level of knowledge and practice of manual therapy among physiotherapy practitioners at the University Teaching Hospital (UTH). Data were collected using a structured questionnaire adapted and modified from previous studies. Data processing and analysis were done using the SPSS version 20.0 for windows. The Chi-square statistical test was used to determine the association of variables and the significance level was set at 0.05 . Respondents that took part in the study were 27 which included 18 females (67\%) with most participants (74\%) having a Bachelor's degree. The majority of the participants (33\%) had 11-15 years of working experience. 59\% of physiotherapy practitioners had average knowledge and $82 \%$ of the participants practiced manual therapy occasionally. Although the majority of the participants in this study occasionally practiced manual therapy most of them had average knowledge about it and preferred other modalities instead. There is a need for physiotherapy practitioners to improve on the knowledge base of manual therapy.
\end{abstract}

\section{Keywords}

Manual therapy, Physiotherapy practitioners, Knowledge, Practice

\section{Introduction}

Manual therapy has been a component of physical rehabilitation programs as early as $400 \mathrm{BC}$, including mobilization/manipulation being a component of physiotherapy practice as well since the inception of the profession [1, 2, 8, 30]. The Guide to Physical Therapy Practice makes it clear that manipulation is within the scope of physiotherapy practice and there is mounting evidence for the use of manipulation in the management of patients with pain in other spinal regions as well as the extremities $[3,4,12,16]$. Physiotherapists are the best healthcare professionals at 
restoring function, and manual therapy can be a major aspect of the treatment protocols $[4,5]$. Most manual therapy approaches advocate that a specific Manual Therapy (MT) technique should be selected based on findings from intersegmental mobility assessment and that localization of the technique to a specific spinal level is pivotal to achieving a positive response to treatment $[6,18,20]$. Evidence is also available supporting the safety and effectiveness of manipulation instruction in the first phase of physiotherapy professional education [7, 38, 40]. Despite the growing body of evidence for manual therapy, it is viewed as a complementary therapy in human medicine by many, even though its effectiveness seems well substantiated and the risks are low. The most likely reason for its slow acceptance is that the skill level required to apply these techniques properly is higher than with traditional therapies, such as exercise or electrotherapy. MT is cost-effective in comparison to other commonly provided interventions and is rarely associated with serious complications [8, 9, 41].

\section{Methods}

\subsection{Design}

A cross-sectional study utilizing a quantitative research method was used and data were collected using an adapted structured questionnaire tailored and modified from a similar questionnaire used by Bello and Lawson [10]. A total of 27 physiotherapy practitioners who work at the university teaching hospital in the physiotherapy department were recruited. Data were sorted, analyzed and interpreted using descriptive statistical methods and it was displayed in tables, bar charts, histograms and pie charts to show relations and patterns of occurrence. Data were analyzed using the statistical package for social sciences software (SPSS) version 20.0 for windows and a chi-square test was used to show associations and a $\mathrm{p}$-value was put on $\mathrm{p}<0.05$. Responses from the questionnaire were converted from nominal to numerical format. The level of knowledge was classified as lacking, minimal, average and adequate while practice will be classified as never, occasionally and regularly.

\section{Results}

According to Table 1, a greater proportion of the sample, $67 \%(n=18)$ was dominated by female participants and the highest percentage of respondents $55 \%(n=15)$ was between $31-40$ years. The largest number of respondents $33 \%(n=9)$ were between 11-15 years of experience in the profession and the statistics also shows that most of the physiotherapy practitioners at UTH are Bachelor of Science holders $67 \%(\mathrm{n}=18)$, followed by diploma holders $26 \%$ $(n=7)$ and a few of them who are Master of Science holders $7 \%(n=2)$ and on where they obtained their current qualification, it shows that $60 \%(\mathrm{n}=16)$ of the physiotherapy practitioners obtained them at the University of Zambia see Table 1 below.

Table 1. Respondents’ Demographic Characteristics (n=27)

\begin{tabular}{|c|c|c|c|}
\hline Variables & Categories & Frequency (n) & Percentage (\%) \\
\hline \multirow{2}{*}{ Gender } & Female & 18 & (67) \\
\hline & Male & 9 & (33) \\
\hline \multirow{4}{*}{ Age } & $21-30$ & 4 & (15) \\
\hline & $31-40$ & 15 & (55) \\
\hline & $41-50$ & 8 & (30) \\
\hline & $50+$ & 0 & $(0)$ \\
\hline \multirow{5}{*}{ Year of experience } & $1-5$ & 5 & (19) \\
\hline & $6-10$ & 6 & $(22)$ \\
\hline & $11-15$ & 9 & (33) \\
\hline & $16-20$ & 5 & (19) \\
\hline & $20+$ & 2 & $(8)$ \\
\hline \multirow{4}{*}{ Highest physiotherapy qualification } & Diploma & 7 & (26) \\
\hline & Bachelors in physiotherapy science & 18 & (67) \\
\hline & Masters of Science in physiotherapy & 2 & (7) \\
\hline & Doctor in philosophy & 0 & $(0)$ \\
\hline \multirow{2}{*}{ Position or rank } & Physiotherapy technologist & 7 & (26) \\
\hline & Physiotherapist & 20 & $(74)$ \\
\hline \multirow{4}{*}{ The institution where obtained the current qualification } & Evelyn hone college & 7 & (26) \\
\hline & University of Zambia & 16 & $(60)$ \\
\hline & Apex medical university & 3 & (11) \\
\hline & Others & 1 & $(4)$ \\
\hline
\end{tabular}




\subsection{Knowledge and practice of manual therapy}

The majority of the respondents have average knowledge regarding the use of manual therapy and they are represented by $59 \%(n=16)$ see Figure 1 below.

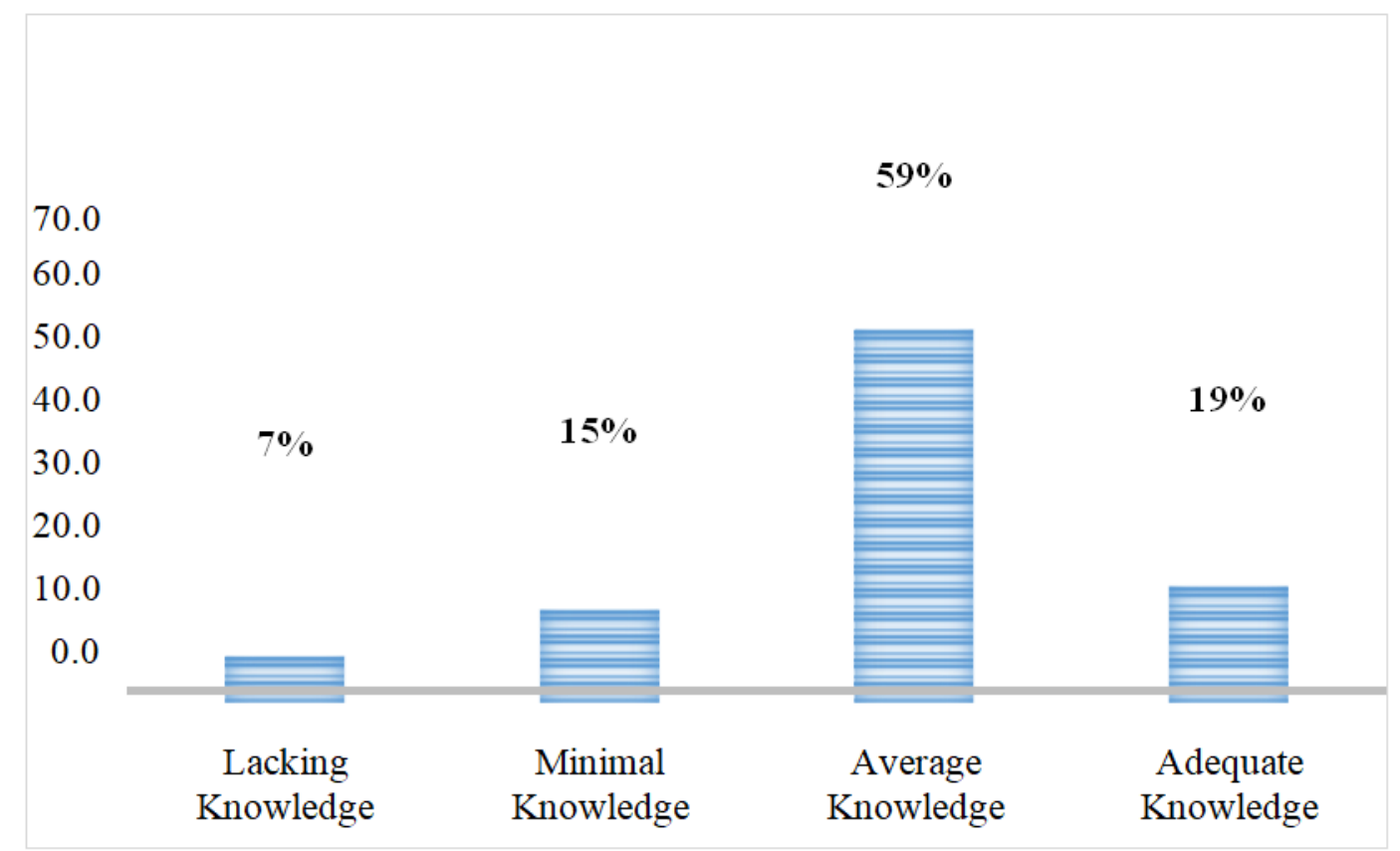

Figure 1. Knowledge regarding the use of manual therapy by physiotherapy practitioners.

See Figure 2 below illustrating the rationale used by physiotherapy practitioners before using manual therapy and the largest number shows that $37 \%(n=10)$ of the respondents use evidence-based.

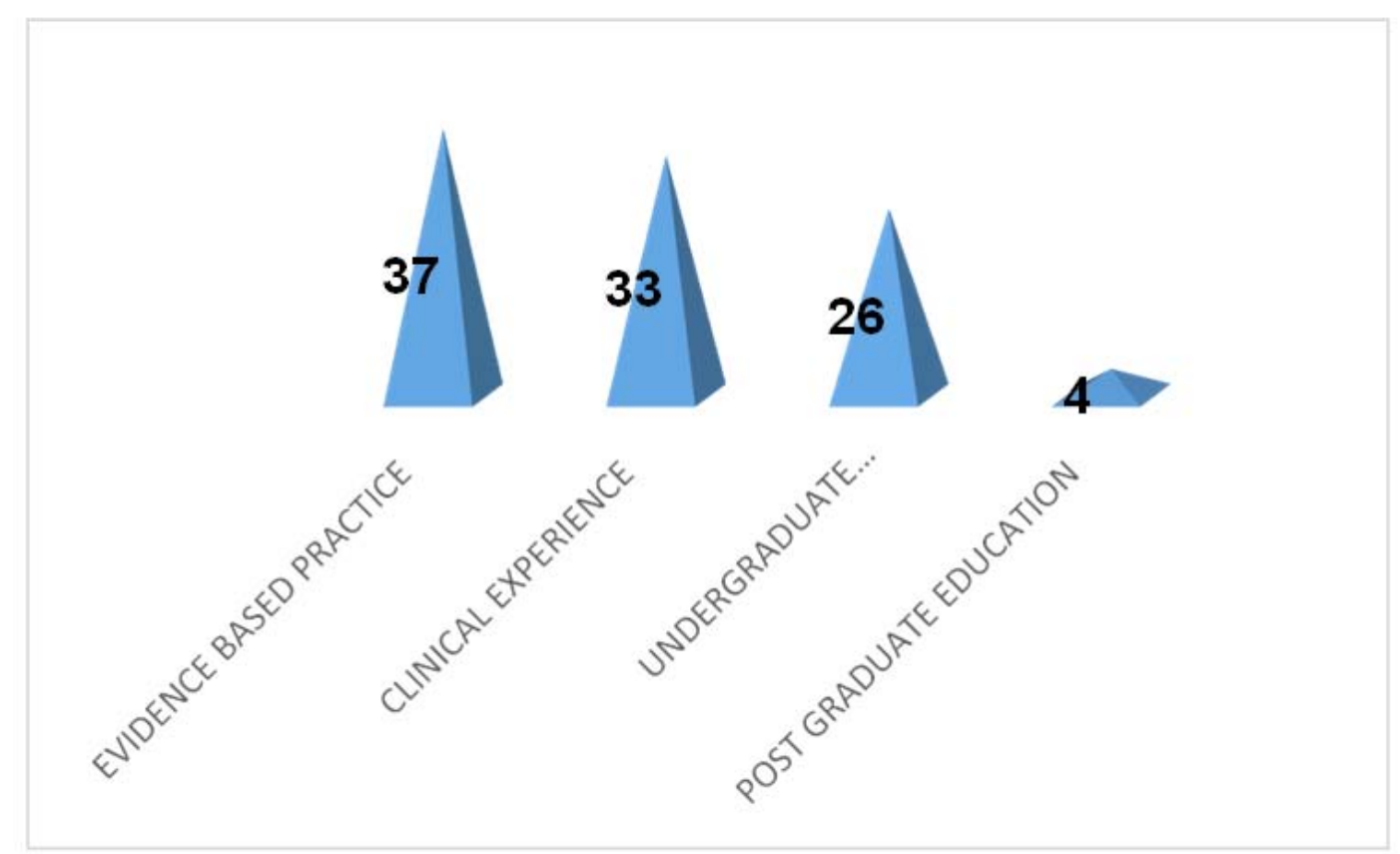

Figure 2. Rationale considered in manual therapy intervention.

The largest number of the respondents represented by $59 \%(n=16)$ use Maitland principles while the $11 \%(n=3)$ represents the statics of those who use none of the physical assessment techniques before using manual therapy see Figure 3 below: 


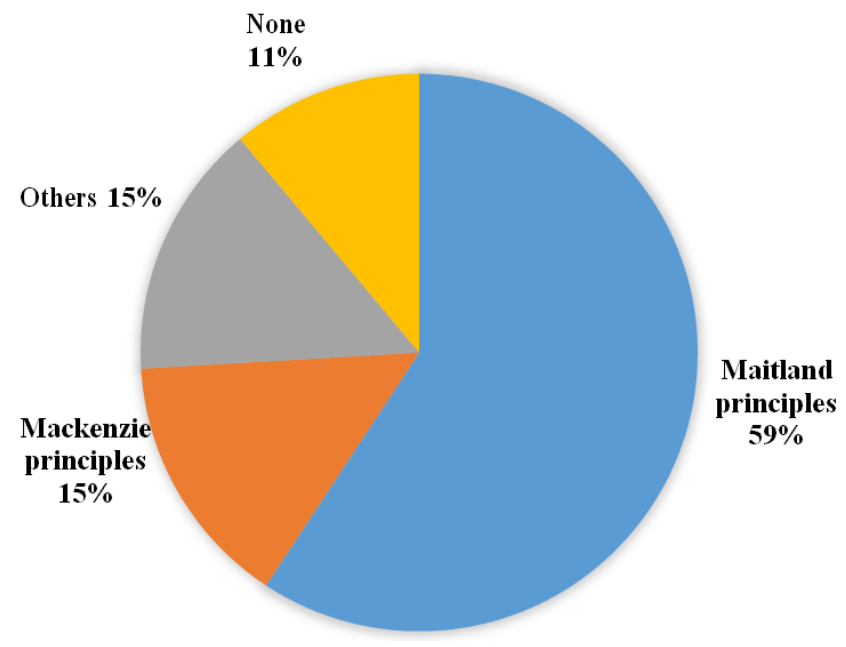

Figure 3. Physical assessment technique used before applying manual therapy.

Therefore, Figure 4 shows the majority of the respondents $82 \%(n=22)$ showed that it is used occasionally while the least $7 \%(n=2)$ showed that it is used regularly and $11 \%(n=3)$ showed that it is never used.

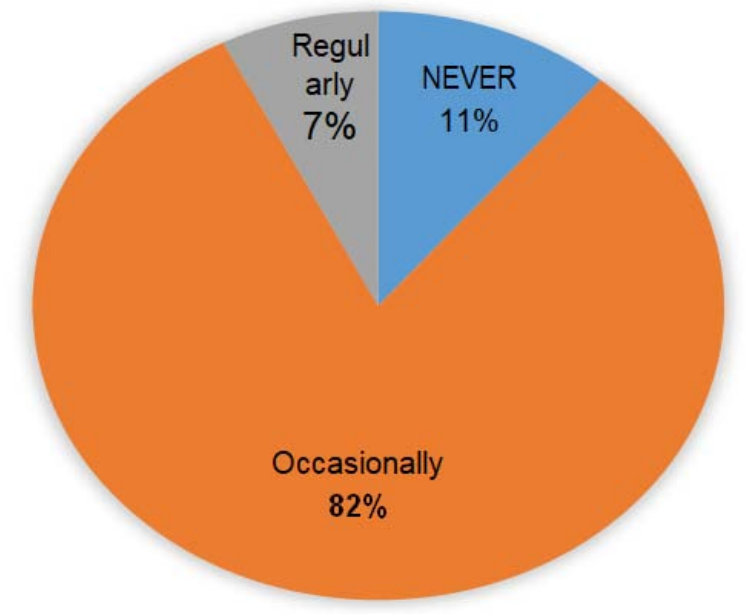

Figure 4. Frequency of manual therapy utilization.

The bar graph below shows that the majority of the respondents treat for 1-4 sessions before recording any improvement with manual therapy and they have been represented by $48 \%(n=13)$, see Figure 5 below:

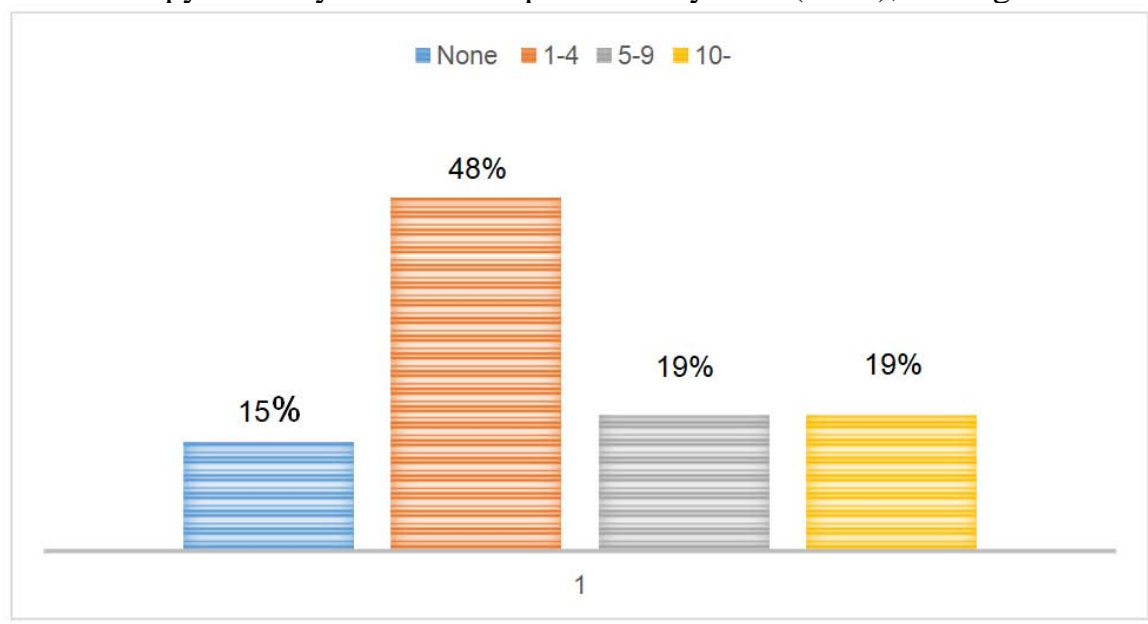

Figure 5. Number of patients who need manual therapy seen in a day. 
The majority of the respondents show $48 \%(n=13)$ that there is a good outcome while the least of the respondents show $4 \%(n=1)$ that there is a poor outcome and $4 \%(n=1)$ that there is missing data. Therefore, see Figure 6 :

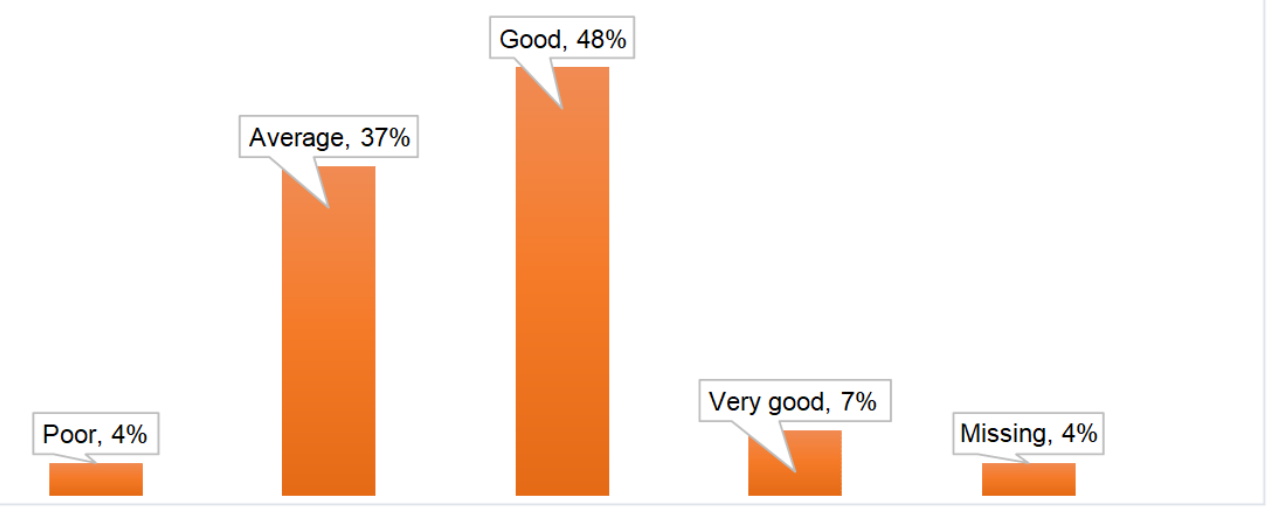

Figure 6. Treatment outcome after using manual therapy.

However, Figure 7 below shows the preference of exercise and electrotherapy to manual therapy that is $88.9 \%$ $(n=24)$ of the respondents showed that the majority prefers electrotherapy to manual therapy whilst $11 \%$ otherwise.

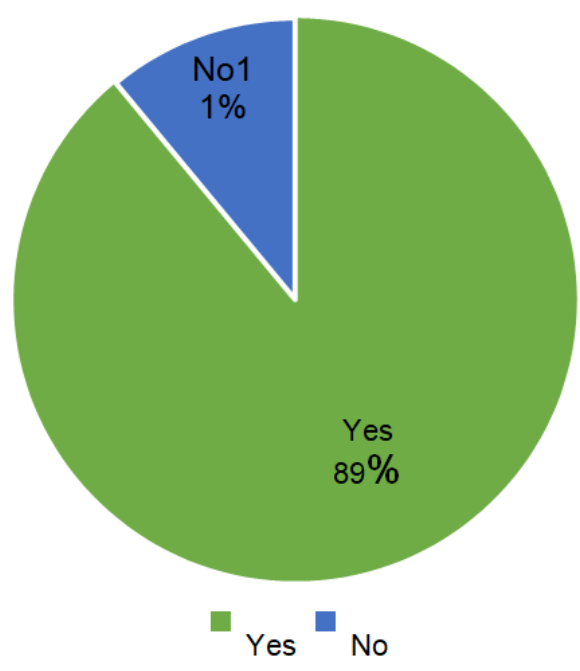

Figure 7. Preference of exercise and electrotherapy to manual therapy.

Table 2. Knowledge regarding treating patients using manual therapy * how frequent is a manual therapy used in treating patients who need manual therapy Cross tabulations

\begin{tabular}{ccccc}
\hline knowledge & & Practice & Statistical values \\
\hline lacking & never & occasionally & regularly & X value (p-value) \\
\hline minimal & 0 & 0 & 0 & $25.585(0.001)$ \\
\hline average & 1 & 3 & 1 & \\
\hline adequate & 0 & 15 & 1 & \\
\hline
\end{tabular}




\section{Discussion}

The current study showed that the majority of the participants had average knowledge about manual therapy and the least statistics showed that the minority lacked knowledge in manual therapy. There are however, gaps in the literature supporting evidence of knowledge among physiotherapy practitioners in manual therapy. The Norwegian Centre for Health Services [21] states that lack of awareness on the clinical implications of evidence-based practice and lack of adherence to principles could lead to failure by physiotherapists to provide evidence of their practice and resultant failure to generate new knowledge on the condition. Similarly, Strutt [23] also found that physical therapists have to be competent in their treatment approach and have to be thorough, knowledgeable and dedicated. Another study conducted by Peersman et al. [25] investigated patients' priorities in outpatient physical therapy and found that the physical therapists being experts in their professional field was the most important aspect for patients. Therefore, the knowledge base must become the object of studies that enable the description and systematization of the subject.

Understanding the rationale behind any treatment requires knowledge of its underlying assumptions and supportive evidence. The majority of participants chose manual therapy interventions based on evidence-based practice knowledge followed by those who chose manual therapy based on knowledge acquired through clinical practice experience, and the least number the participants based their rationale intervention on knowledge acquired on postgraduate training. This is similar to the findings by Connolly et al. [27], who carried out a survey on 115 physiotherapists 12 months after graduating from their professional training regarding evidence-based practice and treatment intervention rationale, and found that $77 \%$ based their intervention on evidence-based practice. This can further be supported by what Jette et al. [31] stated that the knowledge base of physical therapy should be based on science, supported in practice, and further methodically developed.

According to the findings, a larger response showed that Maitland's principles are mostly used followed by Mackenzie techniques. Ali [33] however, did not focus on this area on much by researchers however in a study, the most preferred technique for treating frozen shoulder among physiotherapists is Maitland and the least preferred is McKenzie. This maybe due to the reason that the Maitland mobilization is taught mostly from the third to the final year of Bachelor of physiotherapy at the University of Zambia, and it is covered as a part of their curriculum with specific practical hours [14, 26].

Concerning manual therapy utilization, it was found that the majority of participants occasionally utilized manual therapy in treating patients while the minority showed that they regularly use manual therapy. These findings are contrary to the study carried out by Gracey et al. [35] that there is high use of manual therapy by physiotherapists. The scientific basis in professional practice could further be strengthened through enhanced scientific skills and more easily accessible presentation of the research results and in this study. There however is no evidence to conclude that it is used solely or with other modalities but some evidence from the best of some trials confirms the value of some current physiotherapy practices and the ineffectiveness of others [18-23, 32]. Some little-used interventions are remarkably beneficial. Concerning examining our associations between the knowledge and utilization of manual therapy, it seems reasonable, therefore, we assume that what theory and practice have in common is that the value lies in the actual activity and practice itself constitutes a central source of knowledge $[9,10,16]$.

Physiotherapists usually give exercise therapy, alone or in combination with other treatments, for example, massage, heat, traction, ultrasound, or short wave diathermy [19, 28, 36]. In contrast, our study showed that the Majority of the participants recorded that they preferred exercise and electrotherapy to manual therapy while the minority preferred manual therapy to exercise and electrotherapy. In a similar study, traditionally, the mainstays of physiotherapy management of musculoskeletal pain have been massage, manual therapy, electrotherapy and therapeutic exercise $[4,6,8]$. The study, therefore, concludes that other modalities are preferred to manual therapy despite evidence showing that all modalities should beutilized.

\section{Conclusion}

Given the scarcity of research on physiotherapists' knowledge and practice of manual therapy, it has become critical to develop innovative strategies to close the gap between research and clinical practice. Physiotherapists will be more aware of the importance of manual therapy if their knowledge base is improved, and they will use it more frequently. With a growing international consensus that musculoskeletal pain is a multidimensional disorder involving a complex interaction of factors across the biopsychosocial spectrum that is resistant to change, researchers are increasingly encouraging clinicians to use both specific and nonspecific aspects of treatment to improve outcomes. 


\section{References}

[1] Pettman, E. (2007). A history of manipulative therapy. Journal of Manual \& Manipulative Therapy, vol. 15, no. 3, pp. 165-174.

[2] Zangata, C., Chalwe, M. B., and Mumba, M. S. (2019). Medical students' awareness of the role of physiotherapy in healthcare at the University of Zambia-Ridgeway Campus. Medical Journal of Zambia, 46(4), 343-348.

[3] Paris, S. (2000). A history of manipulative therapy through the ages and up to the current controversy in the United States. J Manual Manipulative Ther., 8(2): 66-77.

[4] Gobbo, M., Lazzarini, S., Vacchi, L., Gaffurini, P., Bissolotti, L., Padovani, A., and Filosto, M. (2019). Exercise combined with electrotherapy enhances motor function in an adolescent with spinal muscular atrophy type III. Case reports in neurological medicine, 2019.

[5] Alexandria Va. (2003). Guide to Physical Therapist Practice, Revised 2nd Ed: American Physical Therapy Association. 36(4): 317-324.

[6] Salian, S. C. and Singh, J. (2016). Perception of Recent Physiotherapy Graduates Regarding Electrotherapy in Undergraduate curriculum content. Int J Physiother Res, 4(2), 1468-75.

[7] Ingeborg, B. C. (2003). Cost-effectiveness of physiotherapy, manual therapy, and general practitioner care for neck pain: economic evaluation along with a randomized controlled trial. BMJ., 326.

[8] Mpemba, M., Shula, H. K., and Chiluba, B. C. (2020). Stroke Disability and Physiotherapy Interventions: A Quantitative Evaluation of Physiotherapy Treatment Approaches' in Zambia. IJDS: Indonesian Journal of Disability Studies, 7(1), 92-100.

[9] Peltzer, K., (2009). Utilization and Practice of Tradition/Complementary/Alternative Medicine in South Africa, African Journal in of CAM, Volume 6, Page: 168-174.

[10] Salati, F. C. (2004). The knowledge and Attitudes of physiotherapists towards patients with HIV/AIDS in the Lusaka Province, Zambia (Doctoral dissertation, University of the Western Cape).

[11] Cleland, J. A., Fritz, J. M., and Whitman, J. M. (2006). Physical Therapists in Patients Who Satisfy a Clinical Prediction Rule: A The Use of a Lumbar Spine Manipulation Technique Case Series. Journal of Orthopaedic \& Sports Physical Therapy, Volume 36, Number 4.

[12] Chiluba, B. C. and Mwansa, M. G. (2019). Disability of Gait in Stroke Survivors: Physiotherapy Clinical Use of Visual Gait Analysis in Lusaka, Zambia. IJDS: Indonesian Journal of Disability Studies, 6(2), 176-183.

[13] Flynn, T., Wainner, R., Fritz, J. (2003). Spinal manipulation in professional level physical therapist education: changing behaviours and monitoring outcomes in the management of low back pain—a case report. PhysTher, InReview.

[14] Nkandu, E. M. (2000). Identifying additional selection criteria for physiotherapy students in Zambia. South African Journal of Physiotherapy, 56(3), 8-11.

[15] Willer, J. C., Dehen, H., Cambier, J. (1981). Stress-induced analgesia in humans: endogenous opioids and naloxone-reversible depression of pain reflexes. Science, 212: 689-691.

[16] Malambo, P. (2005). The physical needs of the elderly with regard to physiotherapy services in the Livingstone district, Zambia (Doctoral dissertation, University of the Western Cape).

[17] Kuraishi, Y. (2008). Neuropeptide-mediated transmission of nociceptive information and its regulation. Novel mechanisms of analgesics, 110(10), 711-772.

[18] Lupenga, J., Namwila, N. N., Nkandu, E. M., Chiluba, B. C., and Shula, H. K. (2019). Evaluating Evidence Based Practice of Physiotherapists and the Quality of Physiotherapy Services in Selected Health Facilities of Lusaka, Zambia. IJDS: Indonesian Journal of Disability Studies, 6(2), 133-142.

[19] Bello, A. I. and Lawson, I. G. (2013). Attitudes and Barriers Towards Engaging in Continuing Professional Development Among Clinical Physiotherapists in Ghana. Internet Journal of Allied Health Sciences and Practice, 11(1).

[20] Musonda, N. and Simpamba, M. M. (2021). A Review of Health Promotion Practices Among Physiotherapists In Africa. Journal of Preventive and Rehabilitative Medicine, 3(1), 14-19.

[21] Norwegian Knowledge Centre for health services. (2005). A guide to clinical practice, NHPC.

[22] Malambo, P. and Marais, M. (2006). Barriers to Utilisation of physiotherapy services among the elderly in the Livingstone District, Zambia. Journal of Community and Health Sciences, 1(1).

[23] Strutt, R., Shaw, Q., Leach, J., (2008). Patients' perceptions and satisfaction with treatment in a UK osteopathic trainingclinic. ManTher., 13: 456-467.

[24] Chuni, V., Chiluba, B. C., Mwango, M., Munalula-Nkandu, E., and Shula, H. (2018). An Exploration of the Knowledge of Informal Caregivers on Ageing Related Health Conditions at Matero and Chawama Old People's Homes, Zambia. International Journal of Neurologic Physical Therapy, 4(1), 1-6. 
[25] Peersman, W., Rooms, T., Bracke, N. (2013). Patients’ priorities regarding outpatient physiotherapy care: a qualitative and quantitative study. ManTher., 18: 155.

[26] Nkandu, E. M., Simpamba, M. M., Shula, H. K., Chisoso, T. L., and Chiluba, B. C. (2020). Physiotherapy Intervention in Palliative Care for HIV Comorbidities: Can it be a Best Practice for Public Policy for Palliative Care in Zambia? Journal of Preventive and Rehabilitative Medicine, 2(1), 92-104.

[27] Conolly, B. T., O’Hare, S. J., Paschall, J. L., Pavia-Smith, M. M., Pitz, A. M., and Gillon, J. F. (2001). Electromyographic activity of selected shoulder muscles in commonly used therapeutic exercises. Physical Therapy, 73: 668-77.

[28] Cromie, J. E., Robertson, V. J., and Best, M. O. (2001). Occupational health and safety in physiotherapy: guidelines for practice. Australian Journal of Physiotherapy, 47(1), 43-51.

[29] Greet M. Rutten, Saskia Degen, Erik. Hendricks Joze, Braspenning Janneje Charting, Rob A. Oostendorp. (2010). Adherence to clinical practice guidelines for low back pain in physical therapy: Do patients benefit? Physical Therapy, volume 90, issue 8, pp. 1111-1112. https://doi.org/10.2522/ptj.20090173.

[30] Hiller, A., Guillemin, M., and Delany, C. (2015). Exploring healthcare communication models in private physiotherapy practice. Patient Education and Counseling, 98(10), 1222-1228.

[31] Jette, D. U., Bacon, K., Batty, C., Carlson, M., and Ferland, A. (2003). Evidence-based practice: beliefs, attitudes, knowledge, and behaviors of physical therapists. PhysTher, 83: 786-805.

[32] Bairaktaridou, A., Lytras, D., Kottaras, I., Iakovidis, P., Kottaras, A., and Chasapis, G. (2021). The role of electrotherapy in the treatment of symptoms of diabetic peripheral neuropathy. Natl J ClinOrthop, 5(2), 27-9.

[33] Ali, K. (2014). What do Swedish physiotherapists feel about research? A survey of perceptions, attitudes, intentions and engagement. Physiother Res Int., 7: 23-34.

[34] Watson, T. (2017). Key Concepts in Electrotherapy. Diaksesdari Electrotherapy. org, 1-9.

[35] Gracey, J. H., McDonough, S. M., and Baxter, G. D. (2002). Physiotherapy management of low back pain: a survey of current practice in Northern Ireland. Spine., 27(4): 406-411.

[36] Salian, S. C. and Singh, J. (2016). Perception of Recent Physiotherapy Graduates Regard-Ing Electrotherapy in Undergraduate Curriculum Content. Int J Physiother Res., 4(2), 1468-75.

[37] Centre for Evidence-Based Physiotherapy. (2001). PEDro (Physiotherapy Evidence Database). http://ptwww.cchs. usyd.edu.au/pedro.

[38] Gobbo, M., Lazzarini, S., Vacchi, L., Gaffurini, P., Bissolotti, L., Padovani, A., and Filosto, M. (2019). Exercise combined with electrotherapy enhances motor function in an adolescent with spinal muscular atrophy type III. Case reports in neurological medicine, 2019.

[39] Koes, B. W., Bouter, L. M., Beckerman, H., van der Heijden, G. J. M. G., and Knipschild, P. G. (1991). Physiotherapy exercises and back pain: a blinded review. BMJ, 302: 1572-6.

[40] Dysvik, E., Kvaløy, J. T., and Natvig, G. K. (2012). The effectiveness of an improved multidisciplinary pain management programme: a 6-and 12-month follow-up study. Journal of Advanced Nursing, 68(5), 1061-1072.

[41] Furlan, A. D., Brosseau, L., Welch, V., and Wong, J. (2000). Massage for low backpain. Cochrane Database Syst Rev., (4): CD001929. 